\title{
Distribution of Radioactive Rainout in Convective Rainfall
}

\author{
F. A. HufF AND G. E. STout \\ Illinois State Water Survey, Urbana, Ill. \\ (Manuscript received 20 April 1964, in revised form 30 July 1964)
}

\begin{abstract}
An investigation was made of the distribution characteristics of radioactive rainout in convective rainstorms through use of data from 29 storms collected on a network of automatic rainwater samplers in central Illinois during spring and summer 1963. Storm profiles of the concentration of radioactive rainout were correlated with rainfall factors and types of synoptic weather. It was found that the storm profiles of rainout could be grouped into four major and three minor types in which the major types accounted for 90 per cent of the cases and the most frequent type occurred 45 per cent of the time. Tentative explanations of the atmospheric conditions under which the major types prevail are presented.
\end{abstract}

\section{Introduction}

During the spring and summer of 1963 , a network of 16 automatic rainwater samplers was operated in central Illinois in conjunction with a research program on the radioactive rainout in convective rainfall jointly sponsored by the Atomic Energy Commission and the Illinois State Water Survey. This research was performed to determine the time and space distributions of storm rainout and the relationship of these distributions to various meteorological factors, particularly the characteristics of the associated rainfall and cloud systems as revealed by radar observations and a network of recording raingages.

Without human attention, ${ }^{1}$ the automatic samplers were capable of collecting 1 to 12 samples of rainwater in a storm. They were calibrated to catch 0.04 inch to 0.06 inch of water in each sample under average conditions of sampler exposure and storm wind speed. Data from the rainwater samplers were supplemented by recording raingage data at each site and by radar observations from PPI and RHI radars.

This paper is devoted to a discussion of the profiles of radioactive rainout through convective storms as revealed by analyses of the automatic sampler data and the relationship of the profile characteristics to rainfall volume, duration, and rate, and to synoptic weather factors.

\section{Data used}

Analyses were restricted to those 1963 storms in which at least four rainwater samples were obtained

${ }^{1}$ Huff, F. A., 1963 : Study of rainout of radioactivity in Illinois. First Progress Report, Contract No. AT(11-1)-1199, Illinois State Water Survey, Urbana, Ill., Jan. with the automatic samplers to define the distribution pattern of radioactive rainout through a storm. Furthermore, analyses were limited to storms in which samples were obtained throughout the life of a storm. With these restrictions, 87 cases from 29 storms were available for study from the spring and summer field operations. Radioactive rainout was measured in terms of gross beta concentration and expressed in picocuries per liter of rainwater.

The 1963 sampling network is shown in Fig. 1. The automatic samplers are labeled "time sampler." The total storm samplers are plastic tubs used to catch samples of the total storm rainfall for use in other phases of the research program. As mentioned earlier, a recording raingage was located at each time sampler. The outer border in Fig. 1 encompasses an area of approximately 6000 square miles used in April and May in support of a nationwide sampling program in cooperation with other agencies involved in research on radioactive rainout. ${ }^{2}$ During June and July, the outer ring of time samplers was removed and the network reduced to approximately 3000 square miles to facilitate servicing and to increase the sampling density on the East Central Illinois raingage network of 50 raingages in 400 square miles (inner area, Fig. 1). The outer ring of samplers was used to activate stations $Q, R, S$ and $\mathrm{T}$ in Fig. 1.

\section{Method of analyses}

A normalizing procedure was employed in the con struction of the storm profiles of gross beta concentra-

\footnotetext{
${ }^{2}$ Huff, F. A., 1964: Study of rainout of radioactivity in Illinois. Second Progress Report, Contract No. AT (11-1)-1199, Illinois State Water Survey, Urbana, Ill., Jan.
} 


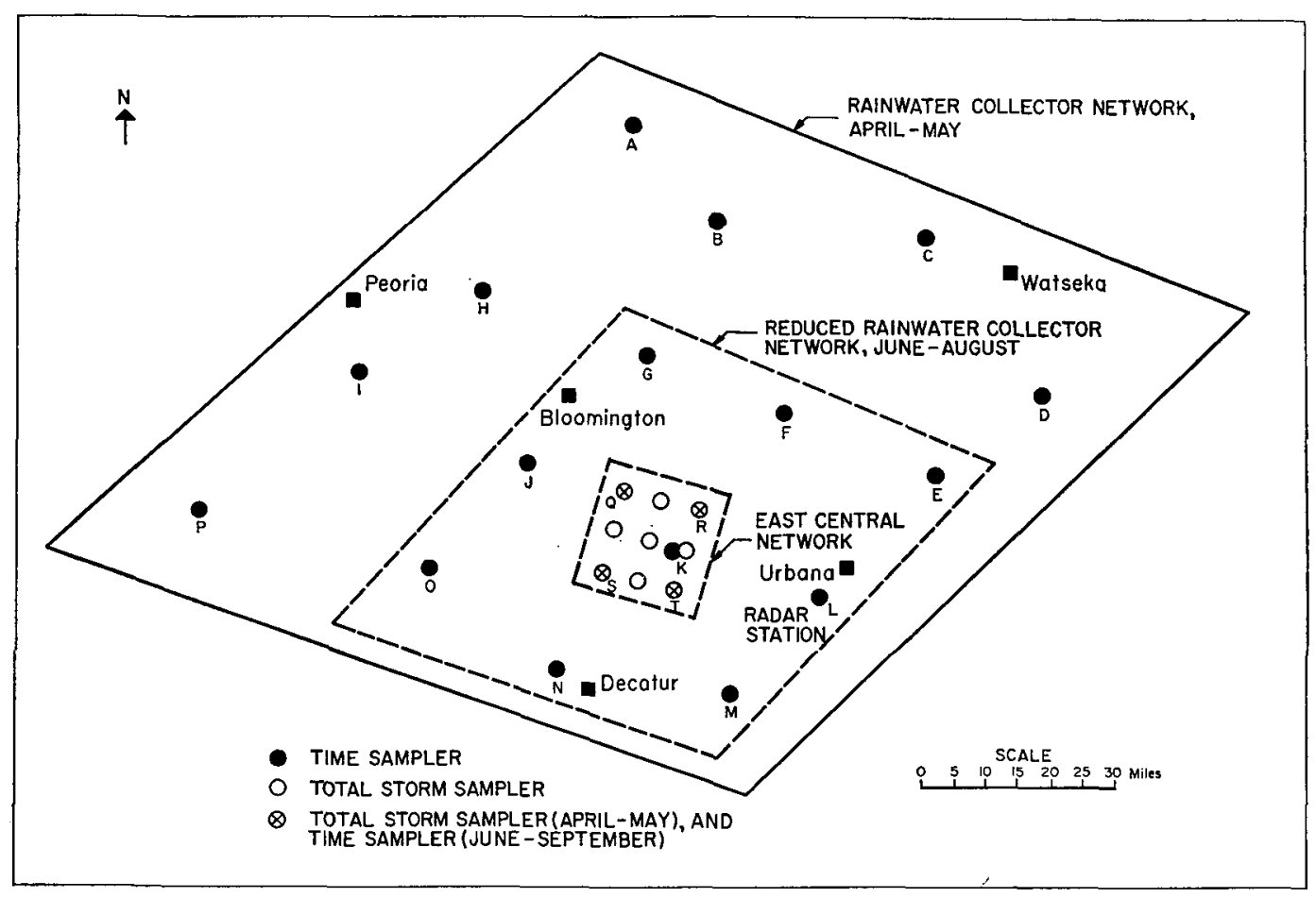

FIG. 1. The 1963 rainwater collector networks in Central Illinois.

tion to permit correlations between stations within particular storms and from one storm to another. In this procedure, the beta concentration in each sample collected at a sampling station was expressed as a ratio to the average beta concentration for the storm. These ratios were then plotted against (1) cumulative per cent of storm rainfall (rain volume) and (2) cumulative per cent of storm duration, as shown in the examples of Figs. 2a and 2b. Curves such as those of Figs. 2a and $2 \mathrm{~b}$ provide a measure of the beta concentration variation with the time and volume distributions of rainfall. Further discussion will be restricted to the volume distributions, since similar conclusions were reached from both types of analyses.

Distribution curves of rainfall rate were constructed for each of the 87 cases through use of the normalizing method discussed above. In the construction of these curves, the ratio of the sample rainfall rate to the average rate for the entire storm was plotted against cumulative per cent of storm rainfall, as shown in Fig. 2c. The rainfall rate curves provide a means of determining whether progressive changes in beta concentration within a storm are related to corresponding changes in rainfall rate, and whether particular types of beta profiles are related to particular types of rainfall rate distribution in storms.

After distribution curves were constructed for each of the 87 cases, ratios were tabulated from the curves at intervals of 5 to 10 per cent of the cumulative per cent of the total storm rainfall as illustrated in Table 1. The curves were also classified by total storm rainfall, rain duration, average rainfall rate, rain type, synoptic type, average beta concentration, and shape of the distribution curve or storm profile.

Average rainfall rate in Table 1 was calculated by dividing the average of the individual sample rates by the number of samples, rather than by the standard method of dividing total storm amount by storm duration. This was done because the distribution curves were determined from the individual samples, and it appeared that in many cases the rate relationship to beta concentration would be masked by the excessive influence that a small amount of rainfall spread over relatively long time (usually at the end of the storm) might have on the rainfall rate determination. The tabulated data illustrated in Table 1 then provided the basic data for the study of relationships between beta storm profiles and meteorological factors.

\section{Beta distribution types}

Examination of the beta distribution curves showed that they could be grouped into four major and three minor types. The four major types accounted for 89 per cent of the 87 cases used in this study. Mean distribution curves for each of the four major types are shown in Fig. 3 (solid lines). Type A was found to occur in 45 per cent of the 87 storm samples. The beta concentration minimum of Type A occurred most frequently when 60 to 80 per cent of the total rainfall had 

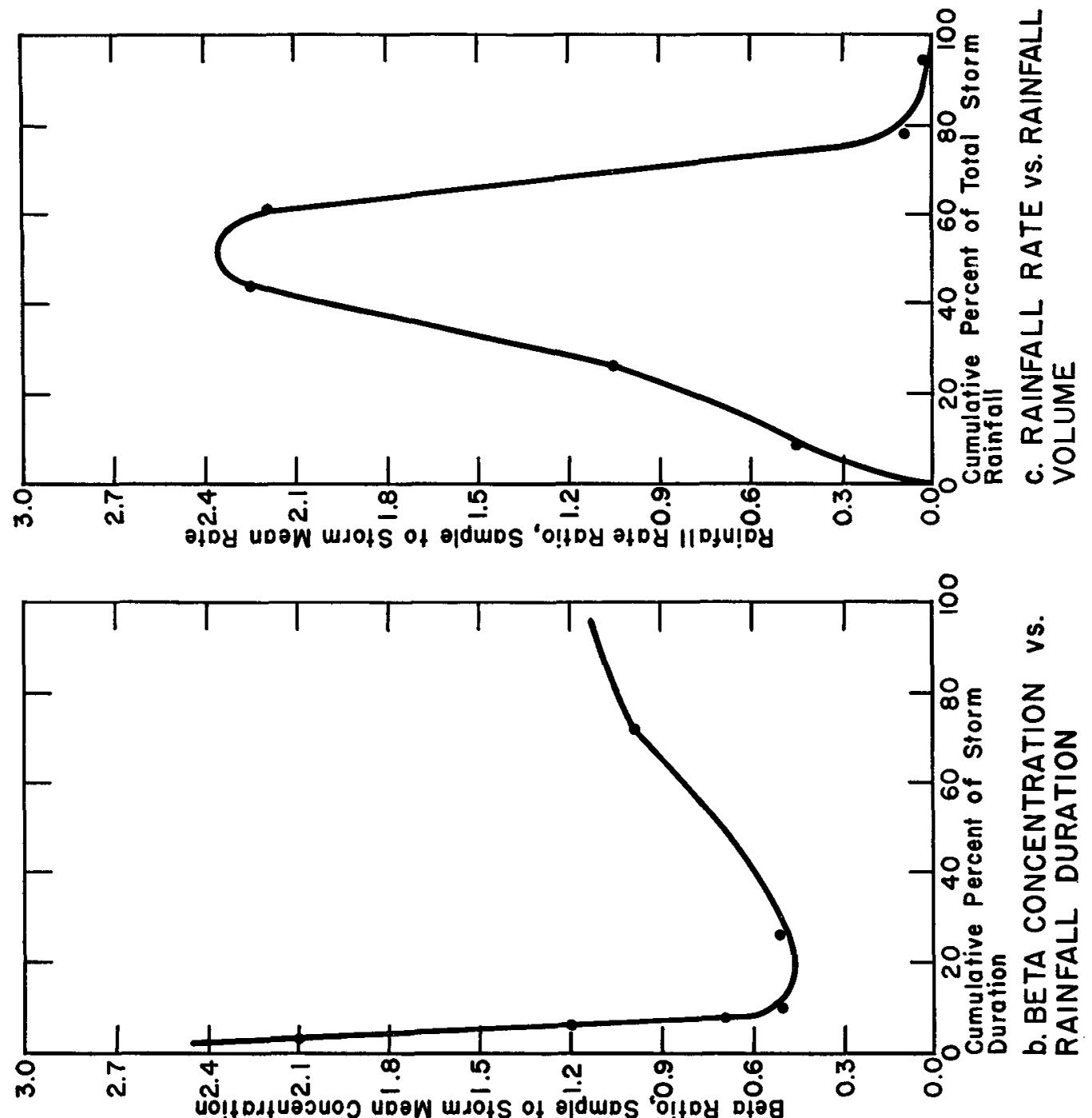

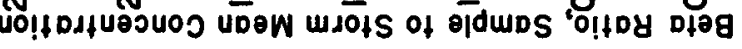

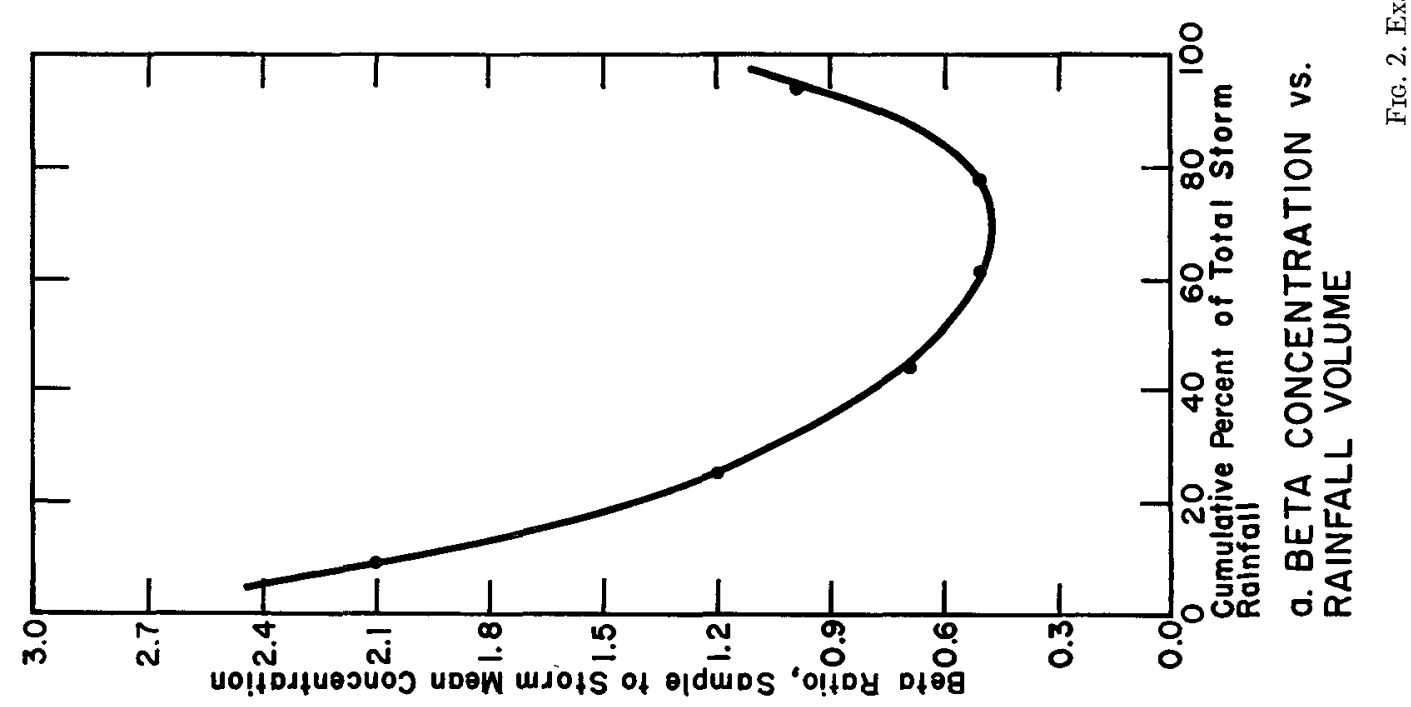



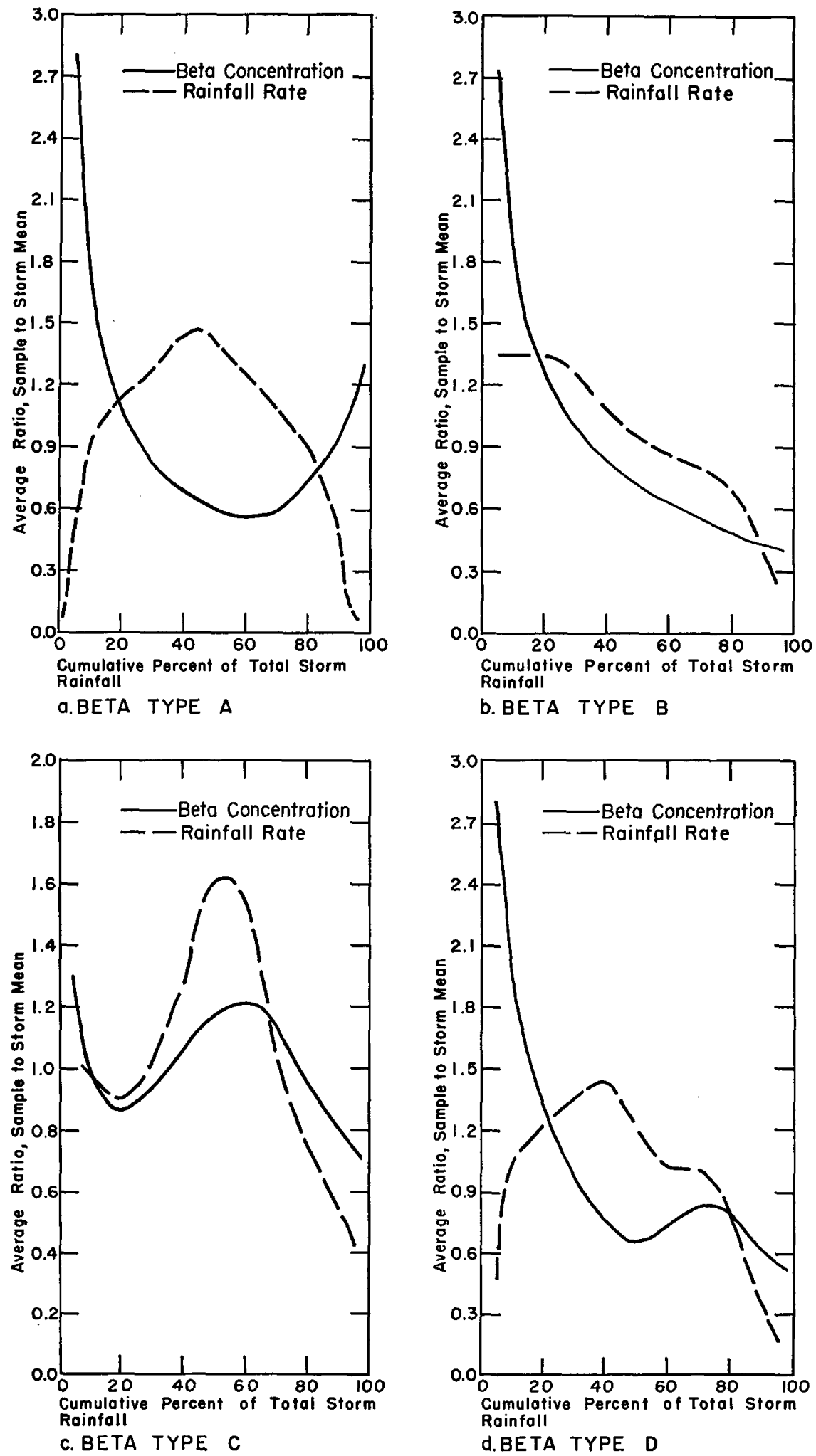

FIG. 3. Average relations for the four major distribution patterns of beta concentration in 1963 storms. 


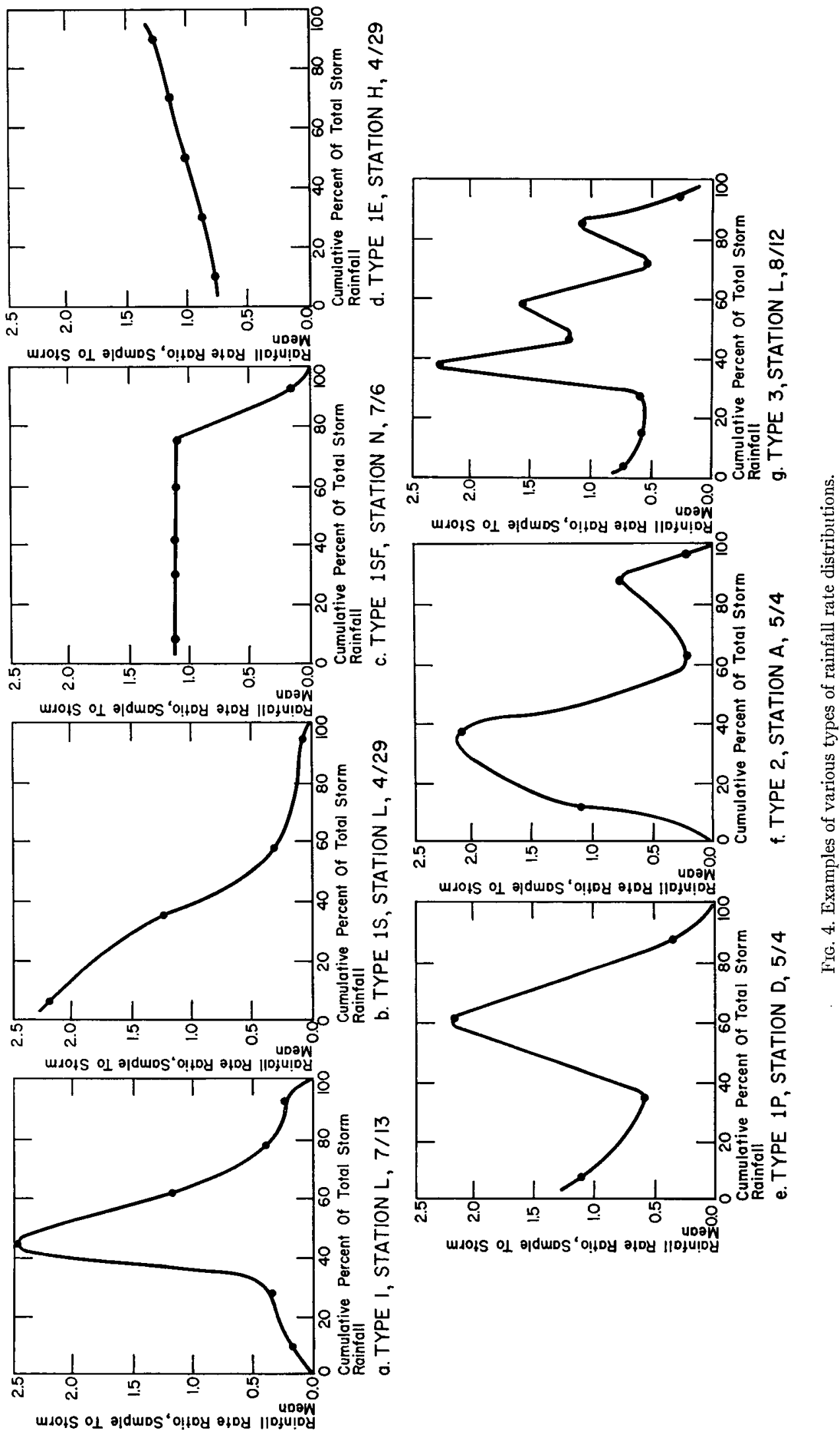


TABLE 1. Summary of beta concentration and rainfall volume distribution for 10 June 1963.

\begin{tabular}{cccccccc}
\hline \hline & $\begin{array}{c}\text { Total } \\
\text { rain } \\
\text { (in.) }\end{array}$ & $\begin{array}{c}\text { Rain } \\
\text { duration } \\
\text { (hr) }\end{array}$ & $\begin{array}{c}\text { Average } \\
\text { rain rate } \\
\text { (in./hr) }\end{array}$ & Rain type & $\begin{array}{c}\text { Synoptic } \\
\text { type }\end{array}$ & $\begin{array}{c}\text { Storm } \\
\text { Beta } \\
\text { shape }\end{array}$ & $\begin{array}{c}\text { average } \\
\text { beta }^{3}\end{array}$ \\
\hline E & 0.39 & 1.1 & 1.03 & TRW, R & CFSL & A & 5123 \\
G & 0.15 & 1.5 & 0.14 & TRW, R & CFSL & C & 9533 \\
I & 0.23 & 1.5 & 0.45 & TRW, R & CFSL & C & 2250 \\
K & 0.20 & 0.9 & 1.07 & TRW, R & CFSL & A & 7447 \\
M & 0.50 & 1.6 & 0.50 & TRW, R & CFSL & A & 4736 \\
N & 0.40 & 1.9 & 1.34 & TRW, R & CFSL & A & 3462 \\
R & 0.23 & 1.3 & 1.12 & TRW, R & CFSL & A & 8833 \\
T & 0.20 & $0.1+$ & 1.50 & TRW & CFSL & A & 4225 \\
\hline
\end{tabular}

${ }^{1}$ TRW-thunderstorm, R-steady-type rain.

2 CFSL-cold front squall line.

${ }^{3}$ Beta concentration in picocuries per liter.

\begin{tabular}{|c|c|c|c|c|c|c|c|c|c|c|c|}
\hline \multirow[b]{2}{*}{ Station } & \multicolumn{11}{|c|}{ Beta ratio for given cumulative per cent of storm rainfall } \\
\hline & 5 & 10 & 20 & 30 & 40 & 50 & 60 & 70 & 80 & 90 & 95 \\
\hline $\mathrm{E}$ & 2.6 & 1.4 & 0.7 & 0.5 & 0.4 & 0.4 & 0.5 & 0.6 & 0.9 & 1.4 & 1.8 \\
\hline $\mathrm{G}$ & - & 0.7 & 0.9 & 1.0 & 1.1 & 1.2 & 1.2 & 1.1 & 1.1 & 1.0 & 0.9 \\
\hline I & - & 0.7 & 0.9 & 1.0 & 1.1 & 1.2 & 1.2 & 1.1 & 1.0 & 0.9 & 0.8 \\
\hline $\mathrm{K}$ & 2.2 & 1.5 & 1.0 & 0.9 & 0.8 & 0.8 & 0.7 & 0.6 & 0.9 & 1.3 & 1.5 \\
\hline $\mathrm{M}$ & 1.7 & 1.3 & 1.0 & 0.9 & 0.8 & 0.7 & 0.8 & 0.9 & 1.0 & 1.1 & 1.1 \\
\hline $\mathbf{N}$ & 2.8 & 1.8 & 1.2 & 0.8 & 0.7 & 0.6 & 0.4 & 0.4 & 0.8 & 1.4 & 2.0 \\
\hline $\mathrm{R}$ & 2.4 & 2.0 & 1.4 & 1.0 & 0.8 & 0.6 & 0.5 & 0.5 & 0.6 & 0.8 & 1.0 \\
\hline $\mathrm{T}$ & 4.5 & 2.2 & 1.4 & 0.7 & 0.6 & 0.6 & 0.7 & 0.8 & 0.9 & 1.0 & 1.0 \\
\hline
\end{tabular}

TABLE 2. Effect of total storm rainfall on beta distribution pattern.

\begin{tabular}{ccccccc}
\hline \hline \multirow{2}{*}{$\begin{array}{c}\text { Cumulative per cent of } \\
\text { storm rainfall }\end{array}$} & $0.11-0.20$ & \multicolumn{6}{c}{ Average beta ratio for given magnitude of total storm rainfall (in.) } \\
\hline 10 & 1.6 & 1.8 & 1.5 & 1.4 & $0.51-0.75$ & $0.76-1.00$ \\
30 & 0.9 & 1.0 & 0.8 & 0.9 & 0.8 & 1.2 \\
50 & 0.8 & 0.8 & 0.8 & 0.8 & 0.7 & 0.9 \\
70 & 0.7 & 0.9 & 0.7 & 0.7 & 0.6 & 0.8 \\
90 & 1.0 & 0.8 & 0.9 & 0.7 & 0.6 & 0.9 \\
\hline
\end{tabular}

TABLE 3. Comparison of beta concentration dist ributions with synoptic weather types.

\begin{tabular}{|c|c|c|c|c|c|c|}
\hline \multirow[b]{2}{*}{ Synoptic type } & \multirow{2}{*}{$\begin{array}{l}\text { Per cent of total } \\
\text { synoptic cases }\end{array}$} & \multicolumn{5}{|c|}{ Per cent of each synoptic type for given beta distribution types } \\
\hline & & Type A & Type B & Type C & Type D & Types B+D \\
\hline Cold front & 24 & 31 & 5 & 36 & 12 & 7 \\
\hline Warm front & 54 & 46 & 68 & 55 & 88 & 74 \\
\hline Air mass & 10 & 10 & 5 & 9 & 0 & 4 \\
\hline Low center & 12 & 13 & 22 & 0 & 0 & 15 \\
\hline
\end{tabular}

occurred. Type B occurred 19 times, or in 22 per cent of the cases. Type C was found 11 times and type D occurred 8 times.

The three minor types accounted for only 10 of the 87 cases. Type $\mathrm{E}$ is intermediate between Types B and $\mathrm{D}$; the beta concentration decreases rapidly in the early part of a storm and then becomes relatively steady throughout the remainder of the rain period. Type $F$ is the opposite of Type B ; that is, the beta concentration shows a general increase in activity from beginning to end of a storm period. Type $G$ is similar to Type $F$, except that a minor peak occurs in the distribution in the early part of the storm, similar to the secondary peak in the latter part of the storm shown by Type D.

\section{Relation between beta distribution and rainfall}

An investigation was made of the effect of total storm rainfall, rainfall duration, and average rainfall rate upon the magnitude of the radioactive rainout through storms as they pass over a given point. This was done for all beta distribution types combined, and for the 39 cases of beta Type A separately. Results indicated that none of these rainfall factors exerted strong control 
over the characteristics of the beta concentration distribution though a storm. Table 2 illustrates the method of analysis and summarizes the results in the evaluation of the effect of total storm rainfall. Table 2 shows that the average ratio differences between rainfall classes were small, in general, and they indicate no distinct trend with increasing storm rainfall.

\section{Relation between beta distribution and synoptic storm type}

The frequency distribution of the 87 storm samples was determined with respect to synoptic type associated with the rainfall. Four basic types of synoptic storms were used; these included storms associated with cold fronts, warm fronts, unstable air masses, and low center passages. Cold frontal rainfall included that associated with both pre-frontal squall lines and with frontal passages. Warm frontal rainfall included precipitation occurring with stationary fronts located south of the sampling network, in addition to rain associated with the approach and passage of warm fronts. Lowcenter rainfall included all storms in which a low center passed through or near the network, usually accompanied by warm and/or cold front passages also. Air mass precipitation included rainfall occurring in the absence of fronts within several hundred miles, and in 1963 was confined to storms occurring in $\mathrm{mT}$ air masses.

The 1963 frequency distribution, expressed in per cent of total cases, is shown in column 2 of Table 3. In columns 3-7 of Table 3 , the percentage distributions of the cases in each of the four major types of beta storm distributions are shown. Column 7 combines Types B and D, since D is similar to B except for interruption of the downward trend in beta concentration throughout a storm by a secondary peak in the latter part of the storm period. The most outstanding departures from the average distribution in Table 3 are those for Types B and D. Twenty-seven cases of these two types were strongly biased toward warm front occurrences in 1963, and, conversely, were associated infrequently with cold fronts. Otherwise, no strong association is indicated between synoptic type and the beta concentration profile through storms.

\section{Relation between beta and rainfall rate profiles}

Rainfall rate was classified according to type of storm distribution in the same manner as the beta distributions. Analyses of the data resulted in division of rainfall rate distributions into the following seven types (as illustrated in Fig. 4):

a) Type 1-a single-peaked profile through the storm resulting from a gradual increase of rainfall rate to a maximum in the storm system, often near the midpoint of the storm with respect to rainfall volume, then a gradual decrease with the rate of decrease becoming less near the end of the storm; b) Type 1S-maximum rate at the start of the storm with gradual decrease throughout the rainfall period;

c) Type $1 \mathrm{SF}$-maximum rate at the start of the storm but continuing nearly constant for a considerable period, followed by a general decrease that is often rapid;

d) Type $1 \mathrm{E}$-gradual increase in rainfall rate to a maximum near the end of the storm;

e) Type $1 \mathrm{P}$-relatively high rate at the start of the storm followed by an appreciable decrease and then a major peak in the central part of the storm;

f) Type 2-two distinct peaks in the rate profile, with the first peak most frequently the major peak;

g) Type 3-three distinct peaks in the rate profile through a storm.

Type 1 occurred most frequently, 37 times or in $43 \%$ of the cases. Type 2 ranked second with 25 cases and $29 \%$ of the total occurrences. With regard to Type 1 , it was found that the rainfall rate peak had its median value at $50 \%$, that is, the peak was reached when $50 \%$ of the rain had fallen. In $81 \%$ of the cases, the Type 1 peak occurred when 35 to $64 \%$ of the rain had fallen.

Next, comparisons were made between the types of beta and rainfall rate distributions. It was found that Type A, the most common beta distribution, occurred most frequently with rainfall rate Type 1 . Of 39 beta Type A storms, 22 or $56 \%$ had rainfall rate Type 1 associated with them. Second in importance was rate type 2 with 6 occurrences.

Rainfall rate Type 2 was associated most frequently with beta Type B, with 9 occurrences out of a total of 19 Type B storms. Of 11 cases of beta Type C storms, 6 had rainfall rate Type 2 distributions, that is, storms with two distinct bursts within the rain period. Four of the 8 cases of beta Type D storms occurred in conjunction with rate Type 1 , the single burst type of storm.

Further analyses of beta Type A distributions revealed a strong tendency for the minimum in the beta curve to be associated with a major peak in the rainfall rate distribution, regardless of the rate type, with the beta minimum lagging the rainfall rate maximum somewhat. This tendency is reflected in the average curves of beta Type $A$ and the average rainfall rate curve for these 39 cases shown in Fig. 3. Thus, on the average, the beta minimum was found to occur at $65 \%$, or after an additional $20 \%$ of the total rain had fallen, following the occurrence of the major peak in the rainfall rate distribution at $45 \%$.

The major rainfall rate peak in a storm is likely to contain rainfall originating in the region in which maximum vertical development of the cloud system took 
place earlier. Assuming an approximately uniform distribution of radioactive debris in the atmosphere, equal depth of convective clouds throughout a storm, and a similar raindrop size distribution throughout the storm, one would tend to find minimum beta concentration in conjunction with the peak rainfall intensity, since there would be a greater volume of rainwater per unit amount of radioactivity in the atmosphere. The minimum concentration of radioactivity would tend to be displaced from the rainfall rate maximum, as indicated in Fig. 3a, if the cloud system in the region in which the maximum rate developed had towered to greater heights than the rest of the storm cloud system, thereby becoming exposed to high-level sources of greater radioactivity. However, if this high-level source of radioactivity were sufficiently intense, a peak instead of a valley would appear in the beta distribution curve in conjunction with the rainfall maximization and produce a Type $\mathrm{C}$ distribution (Fig. 3c).

Beta Type C distributions are the opposite of beta Type A in that they show a peak instead of a minimum (Fig. 3) in beta concentration near the middle part of the storm. Examination of the rainfall rate distributions associated with Type $\mathrm{C}$ storms indicated a strong tendency for a major peak in the inner portions of the storm. A median peak location at 53 per cent of the cumulative rainfall volume was found for the 11 cases (Fig. 3), and, in 10 of the 11 storms, the major rate peak occurred in the range from 35 to 70 per cent. Fig. 3 shows that the beta peak lags slightly behind the rainfall rate peak, on the average, in beta Type $\mathrm{C}$ storms. The major peak in the middle portions of a convective storm appears to be associated with a deep vertical development of the cloud deck into a relatively rich layer of radioactivity. This layer may be encountered through a stratospheric penetration of the cloud deck or through contact with a tropospheric layer recently extruded from the stratosphere, as described by Danielson and associates. ${ }^{3}$ Type $C$ distributions appear to be associated with the initial penetration of a rich layer by a convective storm. Later, as the layer becomes diluted, a Type A distribution is likely to occur.

Type A distributions appear to be representative of distributions in mature convective systems in which any high-level source of radioactivity has been diluted somewhat by earlier penetrations of convective cells. The lagging of the beta minimum from the rainfall rate maximum with the beta Type A distribution is associated apparently with rainfall which follows that produced during the maximum height development of the convective storm, and which, therefore, is more diluted with respect to radioactive debris. The increase in beta concentration following the minimum may then

${ }^{3}$ Danielson, E. F., K. H. Bergman and C. A. Paulson, 1962: Radioisotopes, potential temperature, and potential vorticity, Dept. of Meteorology and Climatology, University of Washington, Seattle, Wash. result from increased evaporation of falling raindrops in the rear portions of the storm, an increased number of available particulates per unit volume of cloud water in the latter stages of the storm, or the downward transfer of stratospheric air in the rear portion of the storm system.

In Type $B$ distributions, the beta concentration reaches a peak at or near the start of a storm period and decreases throughout the storm (Fig. 3). As indicated earlier, the Type 2 rainfall rate distribution was dominant with the beta Type $B$ distributions. In general, the major rate peak with the Type B storms occurred considerably earlier in the rain period than it did with the Type A storms and was not associated with a distinct change in beta concentration, the beta concentration continuing to decrease prior to and following the rate peak. This sequence of events indicates that changes in rainfall rate had little influence on the beta concentration profile in Type B storms, and that the beta concentration was decreasing as the result of cleansing of the atmosphere as the rainstorm progressed. The beta Type B distributions were biased strongly toward association with warm frontal rain. Such rain tends to be more widespread and more continuous than cold front and air mass types, and, therefore, more conductive to a general dilution of the available radioactive debris with time in a storm system. Regardless of the cause, however, the beta Type B distribution results from rainstorm conditions that produce gradual dilution of the beta concentration, and it is a type of distribution that occurs frequently in convective storms.

Beta Type D (Fig. 3) shows a minor peak in the beta concentration following a rapid decrease in concentration in the early portions of the storm. On the average, this peak was found to occur after about 75 per cent of the rain had occurred. Examination of the rainfall rate distributions associated with the eight cases of beta Type D distributions showed no strong tendency for a peak or valley in the distribution corresponding to the beta peak.

Analyses of 1963 storms indicated that more than one type of beta distribution occurred in a particular storm at the various stations in the rainwater network, although a particular type generally dominated. For example, beta Type A distributions. occurred at six of the eight stations for which time samples were obtained on June 10 (Table 1), and beta Type $C$ profiles were recorded at the other two stations. The type of distribution observed at stations in a specific storm may be influenced by several factors, such as spatial differences in the radioactivity in the dry air in the network area, differences in the vertical development of clouds associated with the station rainfall, the age of the convective cells associated with the station rainfall, and the location of the sampling station with respect to the storm center. 
Kruger and Hosler (1963), in a study of Sr-90 concentrations in seven convective showers, have concluded that the concentration in convective precipitation should increase during the development of convective cells, reach a peak when the rainfall from the maximum cloud development reaches the ground, and then decrease as the cell dissipates. Verification of their conclusions is being attempted through the use of beta and Sr-90 data in conjunction with RHI radar data obtained during the collection of rainwater samples on the automatic sampling network (Fig. 1). Results to date have been inconclusive, partially due to the difficulty in isolating single convective cells which pass over network stations in various stages of development. For example, in the storm of 10 June 1963, the network of 16 automatic samplers yielded only four cases which are useful in the verification analyses. In two cases, the concentration of radioactivity appeared to reach a maximum in conjunction with rainfall from the maximum cloud development, whereas in the other two cases, a minimum in the concentration took place near the occurrence of rainfall associated with the maximum cloud development. Through the use of mobile samplers directed from radar storm surveillance during the 1964 sampling period, it is expected that a larger quantity of data will be obtained for studies of relationships between the characteristics of convective cells and radioactive rainout patterns.

\section{Beta concentration at start and end of storms}

As indicated by the preceding discussion of beta profiles, a strong trend was found for relatively high beta concentration at the start of convective storms in 1963. A lesser trend was found for an increase in concentration at the end of storm periods. A trend for relatively high concentrations at the start and end of storms has been found also with 20 cases of Sr-90 time samples. In a study of 73 sets of beta samples from the automatic rainwater collectors, a median of 1.8 was obtained for the ratio of the concentration in the first sample to the concentration in the second storm sample. A median ratio of 1.2 was obtained between the last and next-to-last samples in a storm period. The strong trend for a decrease in the beta concentration at the start of a storm period is revealed by the frequency with which the decrease occurred. A decrease in excess of $10 \%$ occurred between the first and second samples in $80 \%$ of the cases, compared to an increase $8 \%$ of the time, and no change in $12 \%$ of the cases. An increase was found at the end of a storm period in $45 \%$ of the cases, compared to a decrease in $35 \%$ of the storms and no change (10\% or less) $20 \%$ of the timc.

The data were grouped by storm rainfall amount, storm duration, and average rainfall rate. This grouping revealed a trend for the ratio of the initial beta concentration to the storm mean concentration to increase with increasing storm rainfall amount, but this trend was not found for the ratio of the concentration in the last sample to the storm mean concentration. No strong association was found between the ratios and synoptic weather type, through use of the synoptic classification discussed earlier.

Analyses were performed to determine whether the trend for relatively high beta concentrations at the beginning of storm periods prevailed with individual bursts or showers occurring within a storm period comprised of two or more bursts. If not, the occurrence could be assumed to be a boundary condition, and determination of its cause would be simplified. The available data were divided into two groups for this study. In the first, bursts were studied in which rainfall was continuous between bursts, the bursts being identified by decreasing rainfall rate followed by increasing rate later in the same storm period. The second group included all storms in which rain stopped for 0.1 to 1.0 hour between bursts. With the first group, there were 33 cases obtained from storms with two or more bursts. The second group contained 19 cases.

Results of this analysis indicated a much weaker trend for high radioactivity concentrations at the start of bursts within a storm system than at the forward edge of the system. With both groups of bursts, a median ratio of 1.2 was found for the ratio of the first to the second sample with the inner storm bursts, compared to 1.8 with the initial storm bursts in the series. These findings indicate that the high initial ratios are primarily, but not entirely, a border occurrence in convective storms. In turn, this indicates that the high initial concentration may be closely related to evaporation from falling raindrops at the leading edge of the convective system or contamination of the storm fringes by low-level or surface particulates.

It has not been possible to evaluate the role of raindrop evaporation with the available data. However, an analysis has been made of the distribution of particulates in the 1963 rainwater samples in an effort to ascertain whether low-level atmospheric particulates are entrained into the edges of convective systems, particularly the forward edge. This was done through use of selected storms in which tabulations had been made of (1) the weight of particulates in each sample and (2) the intensity of radioactivity in the particulate matter expressed as the number of picocuries per milligram $\left(\mathrm{pc} \mathrm{mg}^{-1}\right)$. The sample particulates referred to here include both radioactive and inactive material captured in the rainwater.

Analyses of 12 storm periods during 1963 have indicated a pronounced trend for the radioactive intensity of particulates to be greater at the end of storm periods than at the start of rainfall. Results of this phase of the study are summarized in Table 4 . In this table, ratios are shown for (1) the rainout intensity in the first rainwater sample $\left(S_{1}\right)$ to the average rainout intensity for the entire storm period $(A)$, and (2) the 
TABLE 4. Comparisons between average beta concentration and average rainwater particulate content in 1963 storm periods.

\begin{tabular}{|c|c|c|c|c|}
\hline \multirow{3}{*}{$\begin{array}{l}\text { Storm } \\
\text { date }\end{array}$} & \multicolumn{4}{|c|}{ Ratio of first and last sample to storm mean } \\
\hline & \multicolumn{2}{|c|}{$\begin{array}{c}\text { Radioactive } \\
\text { intensity } \\
\text { (pc } / \mathrm{mg})\end{array}$} & \multicolumn{2}{|c|}{$\begin{array}{c}\text { Particulate } \\
\text { weight } \\
(\mathrm{mg} / \mathrm{l})\end{array}$} \\
\hline & $S_{1} / A$ & $L / A$ & $S_{1} / A$ & $L / A$ \\
\hline $5 / 4$ & 0.6 & 1.3 & 2.3 & 0.5 \\
\hline $6 / 10$ & 0.8 & 1.5 & 1.9 & 0.6 \\
\hline $7 / 1$ & 0.3 & 1.4 & 3.0 & 0.3 \\
\hline $7 / 6$ & 0.7 & 0.9 & 3.9 & 0.4 \\
\hline 7/13 (A.M.) & 0.8 & 1.4 & 4.6 & 0.4 \\
\hline $7 / 13$ (P.M.) & 1.7 & 1.0 & 1.4 & 1.0 \\
\hline $7 / 20$ & 0.8 & 1.0 & 2.5 & 0.7 \\
\hline $7 / 31$ & 0.6 & 1.2 & 2.8 & 1.0 \\
\hline $8 / 6$ & 0.6 & 1.3 & 3.3 & 0.6 \\
\hline $8 / 12$ & 1.2 & 1.2 & 2.4 & 0.7 \\
\hline $8 / 19$ & 0.6 & 0.9 & 2.6 & 0.9 \\
\hline $8 / 28$ & 0.5 & 1.2 & 2.5 & 0.6 \\
\hline Average & 0.8 & 1.2 & 2.8 & 0.6 \\
\hline
\end{tabular}

rainout intensity in the last sample $(L)$ to the average storm intensity $(A)$. Similar ratios are shown for the particulate weight. The data in Table 4 are averages for the sampler network, and include only storms in which four or more stations provided samples. Also, only stations at which a minimum of four samples was collected in a storm period were used.

Table 4 shows that in 10 of the 12 storm periods the radioactivity intensity ratio was greater at the end than at the start of the storm period. The values in Table 4 are network averages, and departures from the average storm trend occurred at individual stations in some of the storms. For example, in the storm of 10 June three of the twelve stations used in the analysis had an intensity greater at the start than at the end of the storm. Further investigation of possible causes of these reversals within storms is underway.

The pronounced trend for the intensity of radioactivity to be greater at the end than at the start of storm periods indicates that more inactive matter may be in the rainwater at the start of a storm, and, in turn, this indicates that the initial sample may be contaminated by the entrainment of dirt into the forward edge of the storm system from surface or low-level sources. The foregoing suggestion gains further support by the ratios of particulate weight in Table 4 . In all cases, the weight of particulate material is greater at the start of storms, and in most storms the ratio differences from the start to the end of the storm are pronounced.

Summarizing, it appears that in most convective storms the greatest concentration of particulate matter is in the forward portion of the rain zone, and this suggests that the rainwater in this part of the storm may be contaminated by surface or low-level particulates entrained into the advancing storm. In turn, this contamination would tend to increase the beta concentra- tion in agreement with trends discussed earlier. However, the radioactivity of the surface and low-level particulates would be relatively low compared to that of material brought down from high-altitude storage of fission products, since they would include much nonradioactive material as well as previous radioactive dry fallout or rainout material. This should result in a relatively low beta concentration per unit weight of particulates at the start of storms. Continuing the preceding line of thought, one would expect the surface contamination to decrease as a storm is penetrated farther. This should result in a decrease in the total amount of particulate matter per unit volume of rainwater, but the rainout intensity should increase. A general tendency in this direction was found in the 12 storms. Therefore, it is concluded that the relatively high beta concentrations observed at the beginning of a majority of the 1963 rainstorms were partially due to contamination of the rainwater by particulates originating at the surface or in the lower levels of the atmosphere.

\section{Summary and conclusions}

Analyses were made of the distribution characteristics of the concentration of radioactive rainout in convective storms through use of 87 cases of multiple storm samples from 29 storms. It was found that the distribution pattern of gross beta concentration through a storm could be grouped into four major and three minor types, the four major types including approximately 90 per cent of the cases. The most frequent type $(A)$ which accounted for 45 per cent of the cases is characterized by a relatively high concentration at the start of a storm followed by a rapid decrease to a minimum concentration when 60 to 80 per cent of the rain has occurred and then an increase to a secondary maximum near the end of the storm period.

An investigation of the effect of total storm rainfall, rainfall duration, and average rainfall rate during storm periods indicated that none of these rainfall factors exert a strong control on the characteristics of the beta concentration distribution. Two of the major beta types $(B+D)$ were biased strongly toward occurrences with warm fronts; otherwise, no strong correlation was indicated between synoptic weather type and beta concentration profiles in storms.

Rainfall rate was classified according to type of distribution in the same manner as the concentration of radioactive rainout. Comparisons between beta and rainfall rate profiles revealed a strong tendency for the minimum in the beta Type A curve, the most frequently observed type, to be associated with a major peak in the rainfall rate curve, but the beta minimum tends to lag the rate peak. It was found that more than one type of beta distribution may occur at various 
stations in a relatively small area within a convective system, although a particular type usually dominates. Stage of storm development, depth of storm clouds, and, possibly, location of the sampling station with respect to a particular rainshower or thunderstorm in a convective system are factors that may affect the distribution characteristics.

A strong trend was found for relatively high beta concentration at the start of convective storms in 1963. Investigation indicated that the relatively high concentration was primarily a leading edge phenomenon, although a slight trend was found for the beta concentration to increase at the start of succeeding rain bursts within a storm period. Analyses of particulate matter in the rainwater samples throughout 12 storm periods indicated that the leading edge maximum was due partially, at least, to entrainment of surface dirt and/or low-level pollutants into the advancing edge of the storm system.

Acknowledgments. The research discussed in this paper was sponsored by the U. S. Atomic Energy Commission, Fallout Studies Branch, Division of Biology and Medicine.

\section{REFERENCE}

Kruger, Paul, and Charles L. Hosler, 1963 : Sr-90 concentration in precipitation from convective showers. J. appl. Meteor., 2, 379-389. 